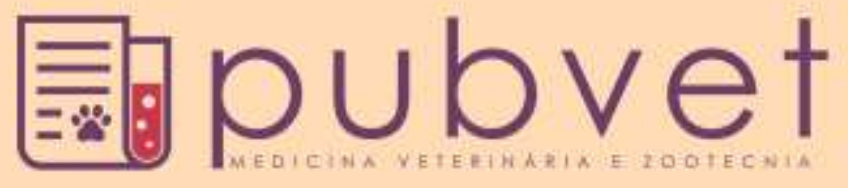

HTTP://DX.DOI.ORG/10.22256/PUBVET.V11N2.159-167

\title{
Patógenos bacterianos em cães com otite externa e seus perfis de suscetibilidade a diversos antimicrobianos
}

\author{
Bruna Gabriela Gheller ${ }^{*}$, Andrea Christina Ferreira Meirelles ${ }^{2}$, Paulo Tadeu Figueira ${ }^{3}$, \\ Vanessa Holsbach ${ }^{4}$
}

${ }^{I}$ Graduanda da Pontifícia Universidade Católica do Paraná, Departamento de Medicina Veterinária, Toledo-PR, Brasil. Email:brunaggheller@hotmail.com

${ }^{2}$ Professor da Pontifícia Universidade Católica do Paraná, Departamento de Medicina Veterinária, Toledo-PR, Brasil. Email:andrea.meirelles@pucpr.br

${ }^{3}$ Professor da Pontifícia Universidade Católica do Paraná, Departamento de Medicina Veterinária, Toledo-PR, Brasil. Email: paulo.figueira@pucpr.br

${ }^{4}$ Mestranda em Ciência Animal pela Universidade Estadual de Londrina, Londrina-PR, Brasil. E-mail: vanessa.holsbach@hotmail.com

*Autor para correspondência

RESUMO. O uso crônico e indiscriminado de antibióticos pode levar à resistência bacteriana, sendo um assunto de extrema importância, pois seu intuito é auxiliar o clínico a identificar o agente causador e tratar adequadamente os casos de otite externa diagnosticados durante a rotina clínica. Os objetivos deste trabalho foram identificar os principais microrganismos presentes na otite externa em cães de Toledo-PR e sua suscetibilidade a diversos antibióticos. Foram coletadas amostras de cerúmen com auxílio de swabs estéreis dos condutos auditivos externos de 50 cães atendidos no Hospital Veterinário da PUCPR, campus Toledo, entre agosto de 2014 e maio de 2015. Os microrganismos foram cultivados e identificados de acordo com os métodos previamente descritos, e a susceptibilidade a antimicrobianos avaliada pelo método de difusão em disco Kirby-Bauer modificado. Os antibióticos testados foram: gentamicina, neomicina, tobramicina, enrofloxacina, ciprofloxacina e norfloxacina. Em relação aos microorganismos isolados dos 18 cães cujas amostras apresentaram crescimento bacteriano, o mais frequente foi Staphylococcus pseudintermedius (55,5\%), Staphylococcus epidermidis (16,6\%), Pseudomonas aeruginosa (11,1\%), Escherichia coli $(11,1 \%)$ e Shigella sonnei $(5,5 \%)$. Observaram-se diferentes percentuais de resistência para cada uma das cinco bactérias encontradas submetidas a seis antimicrobianos. Entretanto, a gentamicina e a neomicina tiveram alta eficácia para todas as bactérias encontradas. Podese concluir que o agente etiológico mais frequentemente isolado foi o Staphylococcus pseudintermedius, e os antimicrobianos mais eficazes frente a esse agente foram gentamicina, ciprofloxacina e norfloxacina. A otite canina é uma enfermidade relevante na prática veterinária, desse modo, é de grande importância o conhecimento do(s) agente(s) associado(s) e seus perfis de susceptibilidade, no intuito de se estabelecer um tratamento direcionado e eficaz e prevenir a disseminação de bactérias multirresistentes.

Palavras chave: Staphylococcus spp., resistência bacteriana, antibiograma, tratamento otitis

\section{Bacterial pathogens found in dogs with external otitis and its susceptibility profiles to several antimicrobial}

ABSTRACT. Chronic and overuse of antibiotics can lead to bacterial resistance, as a matter of extreme importance because its purpose is to help the clinic to identify the 
causative agent and appropriately treat the cases of external otitis diagnosed during the clinical routine. The aims of this study included the identification of the main microorganisms present in external otitis in dogs of Toledo-Brazil and its susceptibility to various antibiotics. Earwax samples were collected with sterile swabs from the external ear of 50 dogs treated at the Veterinary Hospital of PUCPR, campus Toledo, between August 2014 and May 2015. The microorganisms were cultured and identified according to the methods described in this paper, and the susceptibility to antimicrobial was assessed by the diffusion method on modified Kirby-Bauer disk. The antibiotics tested were as follows: gentamicin, neomycin, tobramycin, enrofloxacin, ciprofloxacin and norfloxacin. Regarding the microorganisms isolated from the 18 dogs whose samples showed bacterial growth, the most frequent was Staphylococcus pseudintermedius (55.5\%), Staphylococcus epidermidis (16.6\%), Pseudomonas aeruginosa (11.1\%), Escherichia coli $(111 \%)$ and Shigella sonnei (5.5\%). Different resistance percentages were observed for each of the five bacteria found subjected to six antimicrobials. However, gentamicin and neomycin had high efficiency for all bacteria found. It can be concluded that the most frequently isolated causative agent was Staphylococcus pseudintermedius and the most effective antimicrobial against this were gentamicin, ciprofloxacin and norfloxacin. Canine otitis is an important disease in veterinary practice, thus, it is very important to know the agents associated and their susceptibility profiles in order to establish a targeted and effective treatment and prevent the spread of multi-resistant bacteria.

Keywords: Staphylococcus spp., bacteria resistance, antibiogram

\section{Patógenos bacterianos en perros con otitis externa y sus perfiles de susceptibilidad a diferentes antimicrobianos}

RESUMEN. El uso crónico y excesivo de antibióticos puede conducir a la resistencia bacteriana, siendo una cuestión de extrema importancia, ya que su propósito es ayudar al médico a identificar el agente causal y tratar adecuadamente los casos de otitis externa diagnosticados durante la rutina clínica. Los objetivos de este estudio fueron identificar los principales microorganismos presentes en la otitis externa en perros de Toledo-Brasil y su susceptibilidad a diversos antibióticos. Muestras de cerumen fueron recogidas con hisopos estériles del conducto auditivo externo de 50 perros tratados en el Hospital Veterinario de la Pontifícia Universidade Católica do Paraná campus de Toledo, entre agosto de 2014 y mayo de 2015. Los microorganismos se cultivaron y se identificaron de acuerdo con los métodos previamente descritos, y la susceptibilidad a antimicrobianos fu analisada por el método de difusión en disco de Kirby-Bauer modificado. Los antibióticos testados fueron: gentamicina, neomicina, tobramicina, enrofloxacino, ciprofloxacino y norfloxacino. En cuanto a los microorganismos aislados de los 18 perros cujas muestras presentaron crecimiento bacteriano, lo más frecuente fue el Staphylococcus pseudointermedius (55,5\%), Staphylococcus epidermidis (16,6\%), Pseudomonas aeruginosa $(11,1 \%)$, Escherichia coli (11 1\%) y Shigella sonnei $(5,5 \%)$. Se observaron diferentes porcentajes de resistencia para cada una de las cinco bacterias encontradas y sometidas a seis antimicrobianos. Sin embargo, la gentamicina y la neomicina tuvieron una alta eficiencia para todas las bacterias encontradas. Se puede concluir que el agente etiológico aislado con mayor frecuencia fue Staphylococcus pseudintermedius, y los antimicrobianos más eficaces contra este agente fueron gentamicina, ciprofloxacina y norfloxacina. La otitis canina es una enfermedad relevante en la práctica veterinaria, por lo tanto, es de gran importancia el conocimiento de agente(s) asociado(s) y sus perfiles de susceptibilidad, con el fin de establecer un tratamiento direccionado y eficiente y prevenir la propagación de bacterias multirresistentes.

Palabras clave: Staphylococcus spp., resistencia bacteriana, susceptibilidad a los antibióticos 


\section{Introdução}

A otite externa (OE) é considerada uma afecção do epitélio auditivo e pode também acometer o pavilhão auricular (Bornand, 1992). Essa enfermidade também pode ser conceituada como inflamação, aguda ou crônica, do meato acústico externo com o envolvimento de diferentes agentes etiológicos (White, 1999, Mota et al., 2000, Leite et al., 2003, Rosa et al., 2006) e também de outros fatores que serão abordados posteriormente.

Segundo Cole et al. (1998), as otites caninas podem ser classificadas quanto à sua lateralidade (uni ou bilateral), evolução (aguda, crônica ou crônica recidivante) e localização da inflamação (ouvido externo, médio ou interno). A OE é a mais amplamente estudada, pois é uma das enfermidades mais comuns encontradas na rotina veterinária de animais de pequeno porte e estimase que esta doença afete entre 5 a $20 \%$ dos cães atendidos (Penna et al., 2009, Malayeri et al., 2010). É uma doença que possui alto percentual de recidiva e capacidade de se tornar crônica após suspensão da terapia, situação que está parcialmente relacionada ao uso indiscriminado de antibióticos sem buscar diagnosticar a causa primária (Silva, 2001).

As causas da otite podem estar relacionadas a fatores primários, predisponentes e perpetuantes (Jacobson, 2002). Sabe-se que a microbiota auricular normal dos cães é composta por algumas bactérias e leveduras como Staphylococcus sp. e Malassezia pachydermatis (Girão et al., 2006); porém, essa microbiota pode sofrer alterações de temperatura e umidade, aumentando assim sua proliferação e agindo como um fator perpetuante da otite (Santos, 2007). Dentre as causas primárias podemos citar a presença de ácaros, corpos estranhos, atopia ou causas iatrogênicas. Distúrbios de queratinização, conformação das orelhas e o excesso de pelos no conduto auditivo são considerados fatores predisponentes.

Dentre as bactérias mais encontradas em otites externas podem-se citar as do gênero Staphylococcus, principalmente as espécies pseudintermedius, intermedius e epidermidis, embora bactérias como Pseudomonas aeruginosa, Escherichia coli, Klebsiella peumoniae e Streptococcus spp. também contribuam para a patogênese da otite (Oliveira et al., 2006, Penna et al., 2009, Baptista et al., 2010, Malayeri et al., 2010).
A sintomatologia da otite inclui eritema, odor fétido, dor à palpação, tumefação, prurido, alopecia e presença de cerúmen. Pode-se notar também que o animal apresenta meneios cefálicos.

A escolha do tratamento deve ser realizada com base na cultura e antibiograma, sendo assim o tratamento de cada animal deve ser realizado individualmente, pois pode diferir dependendo do tipo de bactéria presente em cada caso (Silva, 2001). Segundo Jacobson (2002) deve-se realizar a limpeza do conduto auditivo e utilizar terapia antimicrobiana tópica e/ou sistêmica quando necessário. Deve-se ressaltar que são essenciais para o tratamento da doença e consequente diminuição do uso de terapia empírica o conhecimento do agente etiológico baseado na bacterioscopia, cultura e teste de sensibilidade aos antimicrobianos (Silveira et al., 2008). O uso crônico e indiscriminado de antibióticos pode levar à resistência bacteriana, e o presente trabalho tem grande importância neste sentido, pois seu intuito é auxiliar o clínico na identificação dos patógenos e tratar adequadamente os casos de otite externa diagnosticados durante a rotina clínica.

O objetivo deste trabalho foi identificar os principais patógenos bacterianos encontrados em cães com otite externa e seus perfis de suscetibilidade a diversos antimicrobianos na cidade de Toledo-PR.

\section{Material e Métodos}

Entre agosto de 2014 e maio de 2015 foram coletadas amostras de 50 animais provenientes do serviço de atendimento clínico do Hospital Veterinário da Pontifícia Universidade Católica do Paraná (PUCPR), campus Toledo. Todos os animais passaram por consulta e exame clínico para o diagnóstico da otite externa. Após o diagnóstico, utilizaram-se dois swabs estéreis por animal para a coleta do cerúmen, um para o ouvido esquerdo e outro para o ouvido direito. Os swabs foram acondicionados individualmente em tubos estéreis devidamente identificados e posteriormente encaminhados para o Laboratório de Microbiologia do Hospital Veterinário da PUCPR, campus Toledo.

O cultivo foi realizado em placas de ágar sangue e ágar MacConkey. Para isto, o swab com o material coletado foi estriado diretamente em cada uma das placas, que em seguida foram incubadas em estufa à $37^{\circ} \mathrm{C}$ em cultura aeróbia e permaneceram dentro da mesma de 24 a 48 horas para aguardar o crescimento das colônias. Após a 
observação de formação de colônias foi realizado o teste de coloração de Gram para diferenciar as bactérias em gram-positivas e gram-negativas e também para identificar o formato das mesmas. Para a realização deste teste, somente as colônias que estavam isoladas foram utilizadas, as demais foram posteriormente isoladas em outra placa com auxílio da alça de platina. Para a coloração de Gram, foram realizados os seguintes procedimentos:

a. Preparação das lâminas para coloração: uma gota de água estéril foi colocada no centro de uma lâmina limpa. Em seguida, uma alça de platina flambada foi encostada em uma colônia bacteriana e a mesma foi emulsionada na água estéril da lâmina e o material foi fixado após a lâmina ser passada pela chama do bico de Bunsen;

b. O material foi coberto com a solução cristal violeta e deixou-se atuando por um minuto, lavando em água corrente rapidamente após esse tempo;

c. A lâmina foi coberta com o lugol e deixouse atuando por um minuto;

d. o lugol foi removido da lâmina gotejandose sobre a mesma uma solução descolorante de álcool acetona por 15 segundos;

e. A lâmina foi lavada em água corrente e coberta com a solução de fuscina, deixandose atuar por 30-60 segundos;

f. Lavou-se com água corrente e secou-se a lâmina mantendo-a na posição vertical;

g. A lâmina foi observada ao microscópio óptico, usando a objetiva com óleo de imersão (100x de aumento total);

Em seguida, foram realizadas provas bioquímicas para identificação das espécies de bactérias. Utilizou-se os meios MIO (Motidilidade, Indol, Ornitina), TSI (Triple Sugar Iron) e CS (Citrato de Simmons) para identificar as bactérias gram-negativas. Para esta etapa, uma amostra da mesma colônia utilizada para a coloração de Gram foi inoculada nesses meios, que foram posteriormente incubados em aerobiose na estufa à $37^{\circ} \mathrm{C}$ por 24 horas. Após este período, realizou-se a leitura dos meios. Para a identificação das bactérias gram-positivas, observou-se o tipo de hemólise gerada pela colônia no ágar sangue, classificando-as em alfa, beta ou gama hemolíticas. Posteriormente realizou-se o teste da catalase, teste da coagulase e prova bioquímica com manitol.
Após a identificação das bactérias, realizou-se o antibiograma para verificação da sensibilidade aos antibióticos, conforme o método de difusão em disco Kirby-Bauer Modificado (Bauer et al., 1966). Para a realização deste, as colônias foram inoculadas em meio BHI (Brain Heart Infusion) a $37^{\circ} \mathrm{C}$ por 4 horas. Após esse período, foram transferidas para uma placa de petri contendo meio Mueller-Hinton, através da semeadura com o auxílio de um swab. Após, foram colocados seis discos comerciais impregnados com antibiótico distribuídos de forma aleatória, mantendo uma distância razoável de cada disco e incubados por 24 horas em estufa à $37^{\circ} \mathrm{C}$. A leitura foi realizada ao fim das 24 horas, através da verificação do diâmetro do halo gerado pelo antibiótico, o que possibilitou verificar a quais antibióticos as bactérias eram resistentes, intermediárias ou sensíveis. Para esta análise, fez-se a leitura dos resultados com base no halo formado por cada antibiótico. Os antibióticos utilizados foram a gentamicina, a neomicina, a tobramicina, a enrofloxacina, a ciprofloxacina e a norfloxacina.

\section{Resultados}

Dos 50 cães estudados, 18 (36\%) demonstraram colonização bacteriana no ouvido externo, $6(12 \%)$ apresentaram crescimento de fungos e/ou leveduras (12\%), e 26 (52\%) não apresentaram crescimento microbiano. Pelo teste de Coloração de Gram observou-se tanto a presença de bactérias gram-negativas quanto de gram-positivas. Por meio dos testes bioquímicos, foram identificadas as espécies das bactérias, sendo elas: Pseudomonas aeruginosa, Escherichia coli e Shigella sonnei como sendo as negativas, já as gram-positivas encontradas foram Staphylococcus pseudintermedius $e$ Staphylococcus epidermidis.

Em relação aos microrganismos isolados dos 18 cães cujas amostras apresentaram crescimento bacteriano, o mais frequente foi Staphylococcus pseudintermedius $\quad(55,5 \%)$, seguido de Staphylococcus epidermidis (16,6\%), Pseudomonas aeruginosa (11,1\%), Escherichia coli $(11,1 \%)$ e também Shigella sonnei $(5,5 \%)$. Pela leitura dos halos foram identificadas as bactérias que foram resistentes aos antibióticos utilizados. De acordo com a Tabela 1, observamse diferentes percentuais de resistência para cada uma das cinco bactérias encontradas submetidas a seis antimicrobianos. 
Tabela 1. Percentual de resistência a antimicrobianos dos principais agentes bacterianos isolados de exsudato auditivo de cães otopatas atendidos no Hospital Veterinário da PUC/ Toledo - PR, 2015.

\begin{tabular}{lcccccc}
\hline \multirow{2}{*}{ Bactéria } & \multicolumn{6}{c}{ Antimicrobiano } \\
\cline { 2 - 7 } & \multicolumn{2}{c}{ Gentamicina } & Ciprofloxacina Norfloxacina & Tobramicina & Enrofloxacina & Neomicina \\
Staphylococcus pseudintermedius & 20 & 20 & 40 & 70 & 60 & 10 \\
Staphylococcus epidermidis & 0 & 66,6 & 66,6 & 100 & 100 & 0 \\
Pseudomonas aeruginosa & 0 & 0 & 50 & 0 & 100 & 0 \\
Escherichia coli & 0 & 50 & 0 & 100 & 100 & 0 \\
Shigella sonnei & 0 & 100 & 100 & 0 & 100 & 0 \\
\hline
\end{tabular}

A bactéria Staphylococcus pseudintermedius apresentou maiores percentuais de resistência em relação à tobramicina e a enrofloxacina com $70 \mathrm{e}$ $60 \%$, respectivamente. Níveis intermediários de resistência foram encontrados quando utilizados os antimicrobianos norfloxacina (40\%), gentamicina (20\%) e ciprofloxacina (20\%). Já a neomicina teve melhores resultados se tratando desta bactéria, que apresentou somente $10 \%$ de resistência. Os maiores percentuais de resistência da bactéria Staphylococcus epidermidis foram encontrados quando submetidos aos antimicrobianos tobramicina e enrofloxacina, ambos com 100\% de resistência. Quando sujeita aos tratamentos de ciprofloxacina e norfloxacina, a bactéria apresentou níveis elevados, porém ainda assim inferiores aos apresentados anteriormente (66,6\% para ambos). Gentamicina e neomicina foram os mais eficientes para a bactéria em questão com total controle da mesma. Com relação à Pseudomonas aeruginosa, o antibiótico que gerou um resultado de resistência total na bactéria foi a enrofloxacina (100\%), enquanto que $50 \%$ das bactérias tiveram uma resistência intermediária à norfloxacina. A bactéria não apresentou resistência em relação aos antimicrobianos gentamicina, ciprofloxacina, tobramicina e neomicina.

A Escherichia coli apresentou resistência total (100\%) para os antimicrobianos tobramicina e enrofloxacina, enquanto que para a ciprofloxacina a resistência foi intermediária $(50 \%)$ e nenhuma para gentamicina, norfloxacina e neomicina.

Quando submetida aos antimicrobianos ciprofloxacina, norfloxacina e enrofloxacina, a bactéria Shigella sonnei foi totalmente resistente. Já quando sujeita aos tratamentos de gentamicina, tobramicina e neomicina o controle foi total, ou seja, não houve resistência por parte da bactéria. Esta bactéria foi a única que não apresentou percentuais intermediários de resistência, sendo totalmente resistente ou controlada pelos antimicrobianos.

\section{Discussão}

Das 50 amostras coletadas para este trabalho, 24 foram positivas $(48 \%)$ ao crescimento de microrganismos e $26(52 \%)$ foram consideradas negativas. Os casos em que não houve crescimento microbiano se devem ou por problemas na coleta da amostra, transporte, armazenamento ou durante o cultivo, provavelmente. Este estudo corrobora o trabalho realizado por Martins et al. (2011) que em seu estudo clínico e microbiológico de otite externa de cães atendidos em hospital veterinário no noroeste paulista, observou que 214 culturas foram positivas (79\%) ao crescimento de microrganismos e 60 (21\%) foram negativas.

$\mathrm{O}$ isolamento de microrganismos bacterianos a partir de amostras de quadros de otite externa canina é variável. Os microrganismos mais frequentemente isolados na otite externa canina são: Staphylococcus pseudintermedius, Staphylococcus intermedius, Staphylococcus aureus, Pseudomonas aeruginosa, Escherichia coli e os gêneros Streptococcus e Proteus (Matsuda et al., 1984, Ettinger \& Feldman, 2004, Gotthelf, 2007). Outras espécies de bactérias isoladas de OE canina incluem o Staphylococcus epidermidis, Enterobacter sp., Enterobacter aglomerans, Shigella sonnei, Serratia liquefasciens e Klebsiella sp. (Wooley \& Jones, 1983, Magalhães, 1985, Klein \& Müller, 1999, Mota et al., 2000, Nobre et al., 2001, Leite et al., 2003). Tais resultados foram semelhantes com os encontrados no presente trabalho, onde todas as bactérias que cresceram em cultura foram também observadas por demais autores.

Embora alguns estudos considerem os estafilococos coagulase-negativos como principais agentes da OE canina (Lilenbaum et al., 2000), neste estudo o Staphylococcus 
pseudintermedius, bactéria coagulase-positiva, foi a mais frequente (55\%). Semelhante a este trabalho, Martins et al. (2011) observaram em amostras submetidas à cultura bacteriana que $47 \%$ pertenciam ao gênero Staphylococcus. Em outros dois estudos o predomínio desse gênero foi verificado, porém, diferindo do presente trabalho, onde a espécie mais encontrada foi a epidermidis em 31,47\% das amostras (Oliveira et al., 2006, Silveira et al., 2008, Malayeri et al., 2010). Dados do estudo de Oliveira e colaboradores em 2005 indicaram como segundo agente mais isolado a Pseudomonas aeruginosa, diferindo do presente trabalho, pois a mesma foi o terceiro agente mais isolado.

Na prática, o tratamento da otite externa deve ser realizado com limpeza, administração de agentes antimicrobianos e também de antiinflamatórios tópicos (Malayeri et al., 2010); desta forma, é de grande importância a realização de cultura e antibiograma. Em medicina veterinária, algumas classes de medicamentos como aminoglicosídeos e quinolonas têm demonstrado efetividade contra a maior parte das bactérias isoladas de OE canina e têm sido apontados como fármacos de eleição (Greene et al., 1993). Contudo, alguns estudos desenvolvidos ao longo dos anos, demonstram variações nas taxas de resistência contra todos os antimicrobianos, incluindo os supracitados. Essas variações são observadas de acordo com o agente considerado, metodologia empregada e região geográfica de estudo.

Segundo Andrade (2002) para as otites causadas por Staphylococcus sp. são comumente efetivos produtos da classe dos aminoglicosídeos contendo: neomicina, tobramicina, gentamicina ou cloranfenicol. Com relação ao presente trabalho, tanto para $S$. pseudintermedius quanto para $S$. epidermidis, no que tange a neomicina e a gentamicina os resultados foram semelhantes, diferindo apenas quando se tratou da tobramicina, que apresentou elevados índices de resistência (70 e $100 \%$, respectivamente - Tabela 1). Os primeiros relatos com uso de tobramicina in vitro citavam $100 \%$ de eficiência do antimicrobiano contra cepas de Staphylococcus sp. Houve uma redução progressiva desse percentual (Junco \& Barrasa, 2002) e em 2003 encontrava-se em torno de $82 \%$ (Leite et al., 2003). Acredita-se que esse percentual tenha reduzido significativamente, pois dados encontrados neste trabalho apresentaram 0 e 30\% de eficiência para este antimicrobiano em relação às bactérias $S$. epidermidis e $S$.
Pseudintermedius, respectivamente. Essa redução da eficiência deve-se principalmente ao uso indiscriminado de antimicrobianos no tratamento de quadros de otite externa em cães (Oliveira et al., 2008).

Estudos avaliando alguns antimicrobianos da classe das quinolonas como norfloxacina, ciprofloxacina e marbofloxacina descrevem taxas de suscetibilidade superiores a $90 \%$ para cepas de Staphylococcus sp. (Bornand, 1992, Leite, 2003, Silva, 2001, Junco \& Barrasa, 2002). Tais resultados diferem dos apresentados no presente trabalho, onde a norfloxacina apresentou uma eficiência mediana $(60$ e $33 \%)$ para $S$. pseudintermedius e $S$. epidermidis. A ciprofloxacina também apresentou diferentes resultados para a S. epidermidis, com 33\% de eficiência sobre a bactéria. Já para $S$. pseudintermedius, observou-se semelhança aos resultados do trabalho acima mencionado, com uma eficiência de $80 \%$ da ciprofloxacina sobre a bactéria. No tocante à enrofloxacina, observa-se uma redução discreta nos percentuais de suscetibilidade de 98\% (Kiss et al., 1997, Silva, 2001) para $81 \%$ (Junco \& Barrasa, 2002) devido à grande utilização desse fármaco de forma empírica. Estes resultados diferem drasticamente dos observados no presente trabalho, pois para ambas as bactérias os resultados obtidos quanto à eficiência do fármaco foram relativamente baixos (40\% para a espécie pseudintermedius e 0\% para epidermidis).

As cepas de Pseudomonas sp. são as mais frequentemente isoladas dentre os bacilos gram negativos não fermentadores (BGNNF) e possuem maiores taxas de resistência a antimicrobianos na otologia canina (Bornand, 1992, Magalhães, 1985, Oliveira et al., 2005, Mota et al., 2000, Leite, 2003). Quando se trata da espécie Pseudomonas aeruginosa encontrada no presente trabalho, os resultados diferiram dos supracitados, pois dos seis antimicrobianos testados, quatro deles mostraram completa eficácia contra a bactéria.

No tocante aos aminoglicosídeos, do início da década de setenta até o início da década de noventa, a neomicina perdeu cerca de 15 a $30 \%$ de sua eficácia, passando de 100 para 70 e $85 \%$ (Bornand, 1992, Leite, 2003). Valores menores ainda foram encontrados por Kiss et al. (1997) onde o fármaco atingiu um nível de $57 \%$ de eficácia. No tocante a gentamicina, o mesmo fato foi observado. No ano de 1981, a gentamicina mostrava-se $100 \%$ eficaz contra a Pseudomonas 
sp. (Baba \& Fukata, 1981). Porém, esse valor decresceu aos poucos passando por valores de $88,9 \%, 93,9 \%$ e chegando a $65 \%$ (Dakshinkar et al., 1992, Leite, 2003, Kiss et al., 1997, Barrasa et al., 2000), até estabilizar em torno de $60 \%$ de eficiência. Com relação aos outros aminoglicosídeos citados anteriormente, a tobramicina, pertencente à mesma classe, mostra uma eficácia contra mais de $85 \%$ das cepas de Pseudomonas sp. (Oliveira et al., 2008). Quanto à classe dos aminoglicosídeos, os resultados encontrados no presente trabalho diferiram dos supracitados com exceção do fármaco tobramicina.

Com relação aos resultados obtidos para a neomicina e a gentamicina, os mesmos podem ser explicados através do fato deque os fármacos de eleição para bactérias gram negativas, incluindo a $P$. aeruginosa, são as fluorquinolonas e não os aminoglicosídeos (Oliveira et al., 2006). Pode-se supor que a espécie aeruginosa seja uma exceção dentro do gênero Pseudomonas, fazendo com que a neomicina e a gentamicina tivessem uma eficácia completa contra essa bactéria. Já com relação à tobramicina, acredita-se que a exceção aos resultados de trabalhos semelhantes tenha acontecido por este ser um antimicrobiano mais recentemente utilizado para uso tópico na otologia veterinária, não selecionando cepas mais resistentes da bactéria e, consequentemente, não diminuindo sua eficácia. Barrasa et al. (2000) também encontraram resultados semelhantes aos de Oliveira et al. (2006) com relação à eficiência das quinolonas, onde norfloxacina e ciprofloxacina apresentaram resultados superiores a $90 \%$ e $52 \%$ para a enrofloxacina. Tais resultados diferem parcialmente dos encontrados no presente trabalho, com exceção da ciprofloxacina, cujos resultados foram semelhantes. A diferença encontrada quanto à norfloxacina e a enrofloxacina pode ter acontecido devido ao fato de poucas amostras desta bactéria ter sido isolada, conferindo assim uma menor precisão aos dados deste estudo.

Várias espécies de bacilos Gram-negativos da família Enterobacteriacea têm sido isolados a partir de amostras de secreção auricular de cães otopatas (Wooley \& Jones, 1983, Klein \& Müller, 1999, Mota et al., 2000, Nobre et al., 2001, Leite et al., 2003), dentre elas estão duas bactérias que foram encontradas no presente trabalho: Escherichia coli e Shigella sonnei. Entre as enterobactérias, o gênero Proteus sp. tem sido o mais frequentemente observado em amostras de secreção auricular de cães otopatas (Baba \& Fukata, 1981) e será abordado neste estudo como meio de comparação para as enterobactérias encontradas no trabalho, devido à falta de relatos da suscetibilidade das mesmas frente aos antimicrobianos aqui abordados. Com relação ao Proteus sp., as quinolonas têm preservado sua eficiência, com destaque para a norfloxacina e ciprofloxacina (Barrasa et al., 2000). Valores crescentes de resistência têm sido observados apenas para a enrofloxacina, com queda na suscetibilidade de $100 \%$ (Colombini et al., 2000) para $80 \%$ (Leite et al., 2003). Estes resultados diferem em parte dos obtidos neste estudo, principalmente quando se trata da bactéria Shigella sonnei, onde a ciprofloxacina e a norfloxacina mostraram-se suscetíveis $(0 \%$ de resistência - Tabela 1). Para os mesmos antimicrobianos e se tratando da bactéria E. coli, os resultados foram em sua maioria compatíveis com os acima citados, onde a norfloxacina obteve sua máxima eficácia e a ciprofloxacina $50 \%$ de eficácia. Já para o fármaco enrofloxacina, a queda na eficiência é confirmada pelos resultados obtidos neste estudo, porém, as enterobactérias avaliadas foram totalmente resistentes, contrariando a informação supracitada.

Levando em consideração os aminoglicosídeos, a neomicina parece se mostrar constante quanto à eficiência in vitro frente a cepas de Proteus sp., com taxas de suscetibilidade superiores a $80 \%$ (Bornand, 1992, Leite, 2003). O mesmo não se observa com a gentamicina, que demonstrava $100 \%$ de eficácia contra cepas de Proteus sp. e teve esse percentual reduzido ao longo dos anos para 94\% (Bornand, 1992) e, finalmente, $70 \%$ (Leite, 2003). Quando se trata da suscetibilidade da E. coli e da Shigella sonnei frente à neomicina, resultados semelhantes foram obtidos no presente trabalho, onde o fármaco teve uma eficiência de $100 \%$ para ambas bactérias.

Quanto à gentamicina, mesmo tendo seu percentual de eficácia reduzido durante o passar dos anos, a mesma apresentou $100 \%$ de eficácia contra as duas enterobactérias avaliadas neste estudo.

Sabendo-se do aumento da resistência bacteriana no campo da medicina veterinária e também na humana, torna-se necessário o reconhecimento do risco futuro que representa o uso indiscriminado de antimicrobianos. Este fato reforça a necessidade da realização de testes de susceptibilidade a antimicrobianos para escolha 
do antibacteriano a ser utilizado no tratamento dos quadros de OE canina, bem como a importância da monitoração constante dos níveis de resistência bacteriana.

\section{Conclusão}

$\mathrm{O}$ o agente etiológico mais frequentemente isolado foi o Staphylococcus pseudintermedius, e os antimicrobianos mais eficazes frente a esse agente foram gentamicina, ciprofloxacina e norfloxacina. A otite canina é uma enfermidade relevante na prática veterinária, desse modo, é de grande importância o conhecimento do(s) agente(s) associado(s) e seus perfis de susceptibilidade, no intuito de se estabelecer um tratamento direcionado e eficaz e prevenir a disseminação de bactérias multirresistentes.

\section{Referências bibliográficas}

Andrade, S. F. 2002. Manual de terapêutica veterinária. Roca, São Paulo.

Baba, E. \& Fukata, T. 1981. Incidence of otitis externa in dogs and cats in Japan. The Veterinary Record, 108, 393-395.

Baptista, T. C. C., Reis, C. R., Teixeira, D. R. \& Moura, M. 2010. Diagnóstico de Malassezia sp em ouvidos de cães e sua correlação clínica. Revista Eletrônica Novo Enfoque, 9, 48-55.

Barrasa, J. L. M., Lupiola Gomez, P., Gonzalez Lama, Z. \& Tejedor Junco, M. T. 2000. Antibacterial susceptibility patterns of Pseudomonas strains isolated from chronic canine otitis externa. Journal of Veterinary Medicine, Series B, 47, 191-196.

Bauer, A. W., Kirby, W. M. M., Sherris, J. C. \& Turck, M. 1966. Antibiotic susceptibility testing by a standardized single disk method. American Journal of Clinical Pathology, 45, 493.

Bornand, V. 1992. Bactériologie et mycologie de l'otite externe du chien. Schweiz Arch Tierheilk, 134, 1-8.

Cole, L. K., Kwochka, K. W., Kowalski, J. J. \& Hillier, A. 1998. Microbial flora and antimicrobial susceptibility patterns of isolated pathogens from the horizontal ear canal and middle ear in dogs with otitis media. Journal of the American Veterinary Medical Association, 212, 534-538.

Colombini, S., Merchant, S. R. \& Hosgood, G. 2000. Microbial flora and antimicrobial susceptibility patterns from dogs with otitis media. Veterinary Dermatology, 11, 235-239.

Dakshinkar, N. P., Kalorey, D. R., Ganorkar, A. G. \& Harne, S. D. 1992. In vitro sensitivity pattern of bacterial isolates from cases of canine otitis. Indian Veterinary Journal, 69, 1075-1076.

Ettinger, S. \& Feldman, E. 2004. Tratado de medicina interna veterinária: doenças do cão e do gato. Guanabara Koogan, Rio de Janeiro.

Girão, M. D., Prado, M. R., Brilhante, R. S. N., Cordeiro, R. A., Monteiro, A. J., Sidrim, J. J. C. \& Rocha, M. F. G. 2006. Malassezia pachydermatis isolated from normal and diseased external ear canals in dogs: a comparative analysis. The Veterinary Journal, 172, 544-548.

Gotthelf, L. N. 2007. Doenças do ouvido em pequenos animais. Editora Roca, São Paulo.

Greene, C. E., Samperio, J. O. \& Gómez, J. P. 1993. Enfermedades infecciosas: Perros y gatos. Editora Interamericana, São Paulo.

Jacobson, L. S. 2002. Diagnosis and medical treatment of otitis externa in the dog and cat: review article. Journal of the South African Veterinary Association, 73, 162-170.

Junco, M. T. \& Barrasa, J. L. 2002. Identification and antimicrobial susceptibility of coagulase positive staphylococci isolated from healthy dogs and dogs suffering from otitis externa. Journal of Veterinary Medicine, Series B, 49, 419-423.

Kiss, G., Radvanyi, S. Z. \& Szigeti, G. 1997. New combination for the therapy of canine otitis externa I Microbiology of otitis externa. Journal of Small Animal Practice, 38, 51-56.

Klein, B. U. \& Müller, E. 1999. Bakterielles und mykologisches keimspektrum und resistenzverhalten bei der otitis externa von Hunden und Katzen. Kleintierpraxis, 44, 2733.

Leite, C. A., Abreu, V. L. \& Costa, G. M. 2003. Freqüência de Malassezia pachydermatis em otite externa de cäes. Arquivo Brasileiro de Medicina Veterinaria e Zootecnia, 55, 102104.

Leite, C. A. L. 2003. Caracterização clínica e laboratorial de caninos hígidos e otopatas, com ênfase nas microbiotas aeróbica e anaeróbica dos condutos auditivos. Faculdade de 
Medicina Veterinária e Zootecnia. Universidade Paulista, Botucatu.

Lilenbaum, W., Veras, M., Blum, E. \& Souza, G. N. 2000. Antimicrobial susceptibility of staphylococci isolated from otitis externa in dogs. Letters in Applied Microbiology, 31, 4245.

Magalhães, M. J. 1985. Otite externa em caes atendidos no hospital veterinario da UFMG, etiologia, frequencia e sensibilidade antibiotica. Arquivo Brasileiro de Medicina Veterinária e Zootecnia, 37, 333-341.

Malayeri, H. Z., Jamshidi, S. \& Salehi, T. Z. 2010. Identification and antimicrobial susceptibility patterns of bacteria causing otitis externa in dogs. Veterinary Research Communications, 34, 435-444.

Martins, E. A., Momesso, C. S., Nardo, C. D. D., Castro, K. F., Atique, T. S. C., Netto, H. A. \& Furini, A. A. C. 2011. Estudo clínico e microbiológico de otite externa de cães atendidos em hospital veterinário do noroeste paulista. Acta Veterinaria Brasilica, 5, 61-67.

Matsuda, H., Tojo, M., Fukui, K., Imori, T. \& Baba, E. 1984. The aerobic bacterial flora of the middle and external ears in normal dogs. Journal of Small Animal Practice, 25, 269-274.

Mota, R. A., Farias, J. K. O., Silva, L. B. G., Lima, E. T., Oliveira, A. A. F. \& Moura, R. T. D. 2000. Eficácia do Otomax no tratamento da otite bacteriana e fúngica em cães. A Hora Veterinária, 19, 13-17.

Nobre, M. d. O., Castro, Â. P., Nascente, P. d. S., Ferreiro, L. \& Meireles, M. C. 2001. Occurrency of Malassezia pachydermatis and other infectious agents as cause of external otitis in dogs from Rio Grande do Sul State, Brazil (1996/1997). Brazilian Journal of Microbiology, 32, 245-249.

Oliveira, L. C., Carvalho, C., Leite, C. A. L. \& Brilhante, R. S. N. 2008. Comparative study of the microbial profile from bilateral canine otitis externa. Canadian Veterinary Journal, 49, 785-788.

Oliveira, L. C., Leite, C. A. L., Brilhante, R. S. \& Carvalho, C. B. 2006. Etiology of canine otitis media and antimicrobial susceptibility of coagulase-positive Staphylococci in Fortaleza city, Brazil. Brazilian Journal of Microbiology, 37, 144-147.
Oliveira, L. C., Medeiros, C. M. O., Silva, I. N. G., Monteiro, A. J., Leite, C. A. L. \& Carvalho, C. B. M. 2005. Susceptibilidade a antimicrobianos de bactérias isoladas de otite externa em cães. Arquivo Brasileiro de Medicina Veterinaria e Zootecnia, 57, 405408.

Penna, B., Varges, R., Medeiros, L., Martins, G. M., Martins, R. R. \& Lilenbaum, W. 2009. In vitro antimicrobial susceptibility of staphylococci isolated from canine pyoderma in Rio de Janeiro, Brazil. Brazilian Journal of Microbiology, 40, 490-494.

Rosa, C. S., Martins, A. A., Santin, R., Faria, R. O., Nobre, M. O., Meireles, M. C. A., Madrid, I. M. \& Nascente, P. S. 2006. Malassezia pachydermatis no tegumento cutâneo e meato acústico externo de felinos hígidos, otopatas e dermatopatas, no município de Pelotas, RS, Brasil. Acta Scientiae Veterinariae, 34, 143147.

Santos, R. R. 2007. Sensibilidade in vitro da microbiota da orelha de cães com otite externa a cinco antimicrobianos. Acta Scientiae Veterinariae, 35, 433-435.

Silva, N. 2001. Identification and antimicrobial susceptibility patterns of Staphylococcus spp. isolated from canine chronic otitis externa. Arquivo Brasileiro de Medicina Veterinaria e Zootecnia, 53, 1-5.

Silveira, A. C. P., Roldão, C. D. R., Ribeiro, S. C. A. \& Freitas, P. F. A. 2008. Aerobic bacterial flora of the canine otitis. Revista Portuguesa de Ciencias Veterinarias, 103, 567-568.

White, P. D. 1999. Medical management of chronic otitis in dogs. Compendium on Continuing Education for the Practicing Veterinarian, 21, 716-727.

Wooley, R. E. \& Jones, M. S. 1983. Action of EDTA-Tris and antimicrobial agent combinations on selected pathogenic bacteria. Veterinary Microbiology, 8, 271-280.

\section{Article History:}

Received 31 October 2016

Accepted 25 November 2016

Available on line 6 December 2016

License information: This is an open-access article distributed under the terms of the Creative Commons Attribution License 4.0, which permits unrestricted use, distribution, and reproduction in any medium, provided the original work is properly cited. 